\title{
trabalhonecessário
}

issn: $1808-799 \mathrm{X}$

ano 7 - número 8 - 2009

\section{Educacionistas evitarão o apagão da mão de obra qualificada: "Programa de Educação para a Nova Indústria" da CNI}

Thaís Rabello de Souza - thaisrabello@yahoo.com.br

RESUMO: Este artigo trata da suposta crise de falta de mão de obra qualificada no Brasil e a situação da classe trabalhadora diante das prerrogativas da burguesia industrial e do governo federal que favorecem o capital. Discute a parceria públicoprivado situando o SESI e o SENAI dentro da proposta Educação Para a Nova Indústria lançada em 2007 pela CNI. Demonstra que esta vem recebendo total apoio do Senado brasileiro, principalmente do senador Cristovan Buarque, o qual tem se dedicado a disseminar a nova ideologia considerada, pelo mesmo, como capaz de diluir todos os conflitos entre a classe trabalhadora e a burguesia: o Educacionismo. Trabalha com os conceitos de educação-mercadoria, capital humano, qualificação e requalificação profissional para contestar a tese de salvação da educação através da parceria público não estatal. Enfim, destaca que o educacionismo e as propostas da CNI não podem ser concebidas enquanto avanço na democratização do ensino, muito menos enquanto estratégia de Revolução Social a favor da classe trabalhadora.

Palavras-chave: CNI, educacionismo, qualificação, requalificação, formação de capital humano, classe trabalhadora.

\section{Introdução}

\begin{abstract}
"O Brasil como um todo está cheio de "educacionistas", adjetivo que ainda não existe nos nossos dicionários; militantes do "educacionismo", substantivo que os nossos dicionários ainda não adotaram, mas já tem significado: a doutrina que considera a educação como vetor fundamental do progresso defende que a utopia não vem da apropriação do capital dos patrões para os empregados, mas sim de colocar os filhos dos empregados na mesma escola dos filhos do patrão"(BUARQUE, O GLOBO, 16/02/2008, Opinião, p.7, grifos nossos)
\end{abstract}

O ano de 2007, a Confederação Nacional da Indústria (CNI), O IPEA, economistas e alguns educadores participaram de uma série de entrevistas ao jornal 


\section{trabalhonecessário}

issn: $1808-799 \mathrm{X}$

ano 7 - número 8 - 2009

"O Globo" afirmando que o país estaria passando por uma crise de falta de mão de obra qualificada. A alegação para o excesso de vagas ociosas nos postos de trabalho e, contraditoriamente, um número elevadíssimo de desempregados, segundo entrevistados, seria uma conseqüência da crise da educação, fundamentalmente na Educação Básica que afetou diretamente a Formação Profissional.

Consideramos que o desemprego no Brasil deve ser entendido na perspectiva conjuntural, pois a "crise" da educação tem ligações diretas com as políticas públicas oriundas do modelo de Estado burguês, intervencionista e corporativista que vigora no cenário brasileiro sempre a serviço dos interesses privados (Coutinho, 2006).

Para tanto, trataremos, neste texto, da atual proposta educativa da CNI destinada a orientar o governo federal sobre as prerrogativas e os interesses da burguesia nacional do setor industrial através do documento Educação para a nova indústria: uma ação para o desenvolvimento sustentável do Brasil (Disponível em <http://www.cni.org.br/> Acesso em 01/02/2008). O programa tem por objetivo melhorar a educação básica e garantir uma formação profissional de qualidade, via união do Estado à burguesia industrial através de duas esferas do sistema $S$ as quais ofertam ensino para a classe trabalhadora: o Serviço Social da Indústria (SESI) e o Serviço Nacional de Aprendizagem Industrial (SENAI).

A proposta dos empresários, no documento, consistiu buscou promover um consenso em torno da qualificação da mão de obra, onde o SESI e o SENAI enquanto lócus da Educação Básica e Formação Profissional serão as instituições modelo da requalificação da mão de obra desqualificada por culpa da educação básica de má qualidade e da formação profissional em moldes nada flexíveis.

Para tanto, a proposta é suprir $30 \%$ da demanda por educação a qual o governo não consegue absorver. Nesse sentido a desresponsabilização do Estado para com a área educação, principalmente a educação superior onde se formam os trabalhadores altamente qualificados, ocorreu com a imposição da lógica empresarial à formação profissional e abertura de novos cursos sem o devido controle do Estado, além do movimento simultâneo de redução das verbas públicas para o setor (LIMA, 2006) 


\section{trabalhonecessário}

issn: $1808-799 \mathrm{X}$

ano 7 - número 8 - 2009

Neste artigo, entendemos que o discurso neoliberal a favor da democratização da Educação Básica e da formação profissional, esconde o interesse do governo Lula em estabelecer parcerias público-privadas (idem, 2006) de modo a financiar e concretizar a política educacional voltada para combater o analfabetismo atendendo, financeiramente, cada vez menos a educação básica e a superior, e em especial, a formação profissional. Outro interesse deste governo consiste em "abrir o setor educacional para a participação das empresas e grupos estrangeiros, especialmente da educação superior, estimulando a utilização de tecnologias da informação e da comunicação na educação, por meio da educação superior à distância" (idem, ibidem, p.33).

Enfim, para entender a visão dos empresários industriais e do governo, concentraremos nossa atenção no grupo que denominamos como "quarteto fantástico": CNI, SESI, SENAI e o Senado, que via meios de comunicação em massa, vêm anunciando serem capazes de fazer uma Revolução na educação para a classe trabalhadora. O objetivo foi entender a contradição da CNI em desqualificar a educação pública e ao mesmo tempo propor que o SESI e SENAI sustentados pelo governo e os empresários, se tornassem centros de referência. Juntamente com isso, procuramos explicitar em que medida esses órgãos funcionam como mediadores dos interesses da burguesia industrial em termos de manutenção da dualidade estrutural do ensino para a classe trabalhadora. Neste trabalho, trataremos, também, da práxis de alguns intelectuais burgueses que compõem o Senado e estruturam pospostas para a educação em consonância com as demandas do capital, prioritariamente as da burguesia industrial. No contraponto da citação inicial, fica um lembrete sobre o discurso do "quarteto fantástico", antes de adentrarmos no texto propriamente dito:

"[...] a ideologia neoliberal se aproveita de algumas demandas dos movimentos populares, que reinvidicam frente ao Estado, e explora a insatisfação popular diante do caráter cartorial e clientelista do Estado brasileiro. É essa incorporação que permite ao neoliberalismo converter-se em ideologia dominante, cujos efeitos se estendem às classes dominadas. Mas, ao fazer tal operação, o neoliberalismo se apropria e ressignifica demandas e aspirações de parcela das classes dominadas, invertendo-lhes o sentido. Nesse processo de inversão, direitos restritos são convertidos em privilégios e conquistas trabalhistas são consideradas "custos"dos quais as empresas devem imperiosamente se desfazer".(SAES, 2001, aput GALVÃO, 2007) 


\section{trabalhonecessário}

issn: $1808-799 \mathrm{X}$

ano 7 - número 8 - 2009

\section{A ideologia neoliberal do quarteto fantástico: CNI, SENAI, SESI e Senado.}

Numa alusão um tanto quanto cômica, figurativamente, desejamos questionar como o "quarteto fantástico" tem se proposto a atuar no intuito de "salvar" a educação básica e a formação profissional do fracasso. Com projetos que podem ser trágicos para a democratização do ensino voltado para uma formação humana de base politécnica e omnitaletal, seus projetos e idéias são estruturados para promoção de consenso onde o objetivo parece ser ampliar espaços para que a classe dominante recupere sua renda e mantenha seu patrimônio à custa da exploração do trabalho (GALVÃO, 2007).

Primeiramente, representando o herói mais temido do quarteto, o "homem de pedra", afirmamos ter na Confederação Nacional da Indústria (CNI) essa figura. Capaz de se impor pela sua estrutura e força ao representar a burguesia industrial como um todo, se tornou uma "pedra" no caminho classe trabalhadora para que esta obtenha/ mantenha seus direitos sociais. Na década de $90 \mathrm{com}$ FHC, ajudou no desmonte da escola pública quando o governo de FHC priorizou os ajustes fiscais, as reformas estruturais e através da LDB 9394/96 abriu a educação para se configurar como um serviço público não estatal (LIMA, 2006). Ou seja, abriu a educação para a privatização, principalmente nas áreas de formação profissional e do ensino superior, dando margem ao empresariamento da educação (NEVES, 2002).

Dentro da lógica do padrão neoliberal desenvolvimento, a nova ordem foi estabelecer a abertura comercial, privatizar bens e serviços que eram produzidos pelo Estado e desregulamentar as fianças e as relações de trabalho. Essa busca por desenvolvimento via capacitação nacional de se inserir na competitividade do mercado internacional, por parte da burguesia e do governo, "trouxe um aparato científico e tecnológico construído nos anos de desenvolvimentismo para dar conta da estratégia político-econômica de substituição de importações”(idem, 2002). Esse fato ampliou a dependência brasileira subjugando a política nacional a dos países centrais "justamente no momento em que o conhecimento científico e tecnológico 


\section{trabalhonecessário}

issn: $1808-799 X$

ano 7 - número 8 - 2009

passava a se constituir, talvez, no maior instrumento político - tanto para promover a soberania quanto a subordinação nacional-na configuração da atual divisão internacional do trabalho" (idem, 2002).

No caso da América - latina, o avanço da política neoliberal teve por objetivo, segundo BOITO Jr. (2000), ampliar a exploração financeira da região. Isso potencializou a redução de gastos sociais e aumentou os gastos financeiros, conflito principal entre o Estado e as frações da burguesia em geral. Segundo ANTUNES (2005), o governo de FHC manteve a política econômica destrutiva, em conformidade com os interesses do capital globalizado e, conjuntamente, manteve o "traço repressivo" tanto com a classe trabalhadora quanto com a burguesia nacional. Ao descrever a contradição governamental e seu discurso a favor da prioridade com gastos sociais / educação, Antunes afirma que FHC "Propugna autonomia e fortalecimento dos países "em desenvolvimento", e implementa um monumental processo de privatização, de desindustrialização, de desmonte nacional e de integração servil e subordinada à ordem mundializada" (2005, p.42). Ou seja, a política de FHC priorizou a subserviência ao Imperialismo. Esse processo, o qual Boito Jr. definiu como desindustrialização, veio acompanhado da desnacionalização, onde os investimentos estrangeiros na economia nacional fizeram com que o produto interno bruto, em parte, passasse para as mãos do capital estrangeiro (2005, p.48). A política nacional de FHC foi definitivamente "pagar a dívida externa" e ao mesmo tempo abrir as portas para o capital estrangeiro/ financeiro se expandir.

Enfim, neste artigo afirmamos que a atitude contraditória da $\mathrm{CNI}$, enquanto entidade que mais agrega e dissemina as prerrogativas do capital industrial, tem sido tentar apresentar uma pseudo-solução para a crise da falta de qualidade na educação. A juventude em idade escolar nos anos 90 , nos dias de hoje é a que forma o exército de reserva que a indústria atual precisa absorver para sobreviver. $O$ problema é que essa mão de obra não possui saberes suficiente para contemplar satisfatoriamente a indústria, dada a formação profissional com pouca ou nenhuma capacidade de lidar com a ciência e a tecnologia de ponta. E é desta contradição advém o que a CNI está definindo como "falta de mão de obra qualificada", por isso 


\title{
trabalhonecessário
}

issn: $1808-799 X$

ano 7 - número 8 - 2009

faz-se necessário conhecermos as propostas do capital industrial para solucionar o problema, contidas no documento recém lançado.

2. Educação para a Nova Indústria: uma proposta do capital industrial para emancipar ou aprisionar a classe trabalhadora?

\begin{abstract}
"A educação é uma das vertentes fundamentais para o crescimento da economia, seja pelo efeito direto sobre a melhoria da produtividade do trabalho - formação de trabalhadores mais eficientes, capital humano - seja pelo aumento da capacidade do país de absorção e geração de novas tecnologias. O posicionamento competitivo da indústria brasileira está apoiado na agregação de valor e na inovação. É imprescindível prover um ambiente de geração e disseminação de conhecimentos em grande escala, fundado no acesso amplo às tecnologias de informação e comunicação (TICs), no desenvolvimento de competências profissionais adequadas às necessidades do setor produtivo e no fomento ao empreendedorismo e à criatividade". (CNI, 2007, p.09)
\end{abstract}

O documento Educação para a nova indústria é oriundo do Mapa estratégico da Indústria 2007-2015, onde houve a tentativa de "prever" o futuro econômico do país e as estratégias que deverão garantir o crescimento do capital industrial tanto no mercado interno quanto no externo. O SESI e o SENAI, dentro da proposta, foram considerados os propulsores da formação de mão de obra qualificada, um exemplo para o país. Foram considerados como aqueles que poderão materializar o que a CNI denomina "forças da mudança" para tornar a indústria mais competitiva. Essa fórmula mágica se constitui na soma dos fatores: nova territorialidade da indústria, novos conteúdos, atualização tecnológica, modernização infra-estrutura, aprendizagem flexível, inovação (2007, p.19).

A primeira diz respeito aos "Novos Perfis Profissionais", já que o principal elemento limitador do crescimento do país parece ser o baixo nível de escolaridade. Portanto, foi preciso traçar ações para elevação da escolarização e capacitação profissional através da difusão de novas técnicas de produção; padrões de gestão (qualidade total, segurança no trabalho, economia de tempo e de materiais, gestão ambiental e de desenvolvimento); tendência de maior escolaridade e crescente preocupação das empresas por treinamento e capacitação. 


\section{trabalhonecessário}

issn: $1808-799 X$

ano 7 - número 8 - 2009

A segunda às "Novas regiões Industriais". A idéia foi priorizar a interiorização e criação de novos pólos industriais no Norte, Nordeste e Centro-Oeste. Para tanto será necessário atender às demandas de formação de recursos humanos. Daí o SESI e o SENAI atuarem efetivamente como centros de formação de capital humano. Os pontos centrais da primeira força são a: modernização das escolas, nos novos conteúdos de formação, na educação à distância, na aprendizagem flexível, na educação empreendedora e educação na empresa. Logo, a combinação da primeira com a terceira, ou seja, com as "Novas Tecnologias", poderá permitir seguir as tendências internacionais priorizando cursos generalistas para em seguida no âmbito da empresa, fazer o aprofundamento da especialização de acordo com os novos padrões tecnológicos (2007, p.16).

Devido à reestruturação da educação para atender às demandas do avanço tecnológico, a quarta força, ou seja, a Aceleração do Ritmo de Crescimento necessitaria de uma grande oferta de trabalhadores qualificados. A previsão é de 500 mil novos técnicos, com diferentes formações, até 2010. Para tanto as metas foram atingir 16,2 milhões de matrículas no período de $2007-2010$, sendo $7,1 \%$ via SESI com a educação básica e continuada; e 9,1\% via SENAI com a educação profissional. Logo, o programa atual da CNI traz como elementos centrais:

- "expansão e diversificação da oferta de educação básica, continuada e profissional ajustada às necessidades atuais e futuras da indústria;

- modernização, otimização e adequação da infra-estrutura física das escolas e laboratórios;

- flexibilização no formato e metodologias de atendimento às demandas educacionais da indústria;

- capacitação de docentes, técnicos e gestores em tecnologias e gestão dos processos educacionais."(idem, ibidem, p.20)

Enfim, o programa como um todo apresentou dois eixos bem definidos: a Educação Básica e Continuada pelo SESI e a Educação Profissional pelo SENAI enquanto mediadores da formação de mão de obra qualificada.

"O capital humano nas organizações, considerado na sociedade do conhecimento
como o principal ativo das empresas, é formado pelo conjunto de habilidades que
as pessoas detêm, adquiridas por meio de processos educativos, treinamento ou
da experiência. As chamadas competências básicas, formadas pela educação
básica e a continuada, são condição para o desenvolvimento das demais
competências, inclusive as profissionais, na medida em que possibilitam continuar
aprendendo e aperfeiçoando-se durante toda a vida. Tais aspectos têm adquirido
crescente importância nas ações voltadas para o desenvolvimento socioeconômico 


\section{trabalhonecessário}

issn: $1808-799 X$

ano 7 - número 8 - 2009

e a melhoria da qualificação do perfil dos trabalhadores da indústria. A indústria competitiva. depende de força de trabalho capacitada, o que implica melhorar os índices de escolaridade do trabalhador e garantir aos seus filhos educação de qualidade. O programa Educação para a Nova Indústria compreende todos esses temas. "(2007, p.21)

\subsection{SESI e a educação básica: a lógica da inclusão excludente}

O SESI atua diretamente ofertando educação básica e dentro desta alguns cursos profissionalizantes a nível de $2^{\circ} \mathrm{grau}$. Suas principais linhas de ação são:

- A escola de tempo integral cujo objetivo é educar "possibilitando ao aluno adquirir hábitos de vida saudável, ampliar o capital cultural, incentivar a leitura, conhecer novos idiomas, participar de processos de inclusão digital e de formação profissional". (2007, p.22).

- A educação continuada entendida como um processo "permanente de aprendizado e de incorporação de conhecimentos gerados pelo progresso científico e tecnológico, propiciando o desenvolvimento pessoal e profissional. [...] O programa tem, pois, como objetivo prover conhecimentos alinhados às necessidades da indústria com conteúdos típicos da Rede SESI de Educação (competências básicas, empreendedorismo, responsabilidade social, sustentabilidade ambiental, ética, inovação, educação alimentar, inclusão digital)". (2007, p.23)

- SESI Indústria do Conhecimento: "O programa é uma proposta inovadora de promoção de acesso ao conhecimento, especialmente em comunidades de baixo IDH. São unidades multimeios, compostas de 10 computadores com acesso à Internet, biblioteca com livros impressos e virtuais, DVDteca, GIBIteca. É uma parceria, de âmbito nacional, entre o SESI e os Ministérios da Educação e das Comunicações e, localmente, com prefeituras, empresas, entre outros" (2007, p. 26).

- Prêmio SESI Qualidade da Educação: "Este prêmio tem como objetivo reconhecer as melhores escolas de educação básica em todo o Brasil, apoiando processos de melhoria. É resultado de uma parceria do SESI, UNESCO e o Movimento Todos pela Educação, com o apoio do Ministério de Educação". (2007, p.27-28)

- A Consultoria para Educação de Qualidade: "apóia processos de melhoria, qualificando gestores e promovendo o intercâmbio de experiências. $O$ Programa tem como objetivo assessorar escolas e redes de ensino estaduais e municipais, para a elaboração de planos de melhoria" (2007, p.28).

Relembrando que estamos tratando das estratégias do cômico-trágico "quarteto fantástico" que se propõe a salvar a educação brasileira, afirmamos que o SESI pode representar a figura da "mulher invisível". Ele aparece em determinadas propostas como uma alternativa para a educação pública desqualificada, mas no conjunto de propostas que visam melhorar a situação do aprendizado da classe 
issn: $1808-799 \mathrm{X}$

ano 7 - número 8 - 2009

trabalhadora, o SESI desaparece por completo porque seu destino é ofertar o básico em termos de educação para formar um determinado tipo de trabalhador. Este se obtiver condição financeira, poderá prosseguir com os estudos via SENAI. Seus cursos são gratuitos, mas entende-se que por trás dessa morosidade generosa opera-se uma inclusão excludente (KUENZER, 2002) que manterá um ensino dual ao mesmo tempo em que dá a impressão de que os anseios da classe trabalhadora estariam sendo atendidos.

2.2. SENAI e a formação profissional: a lógica da exclusão includente

Ao tratarmos do SENAI, é preciso salientar que esta instituição desenvolve suas atividades com a finalidade de acompanhar as inovações tecnológicas associadas às novas formas de organização da produção. Portanto, atualizar e gerar "recursos humanos" tem sido seu maior objetivo. Portanto, educar o cidadão (FRIGOTTO. CIAVATTA. 2006) para que ele se torne emancipado está fora de questão.

Para esta instituição, educação profissional é: “... a maneira de emancipar o indivíduo pelo trabalho. O projeto educacional visa à formação de cidadãos capazes de atuar de maneira autônoma, crítica, consciente e participativa no ambiente de trabalho e na vida cotidiana" $(2007$, p.28). Dentre os pontos mais relevantes das futuras "tarefas" do SENAI, destacamos:

- A Formação Inicial e Continuada dos Trabalhadores: "compreende ações de aprendizagem industrial, iniciação, qualificação, aperfeiçoamento e especialização profissional (2007, p. 28).

- Aprendizagem industrial: "É o principal compromisso do Senai para o atendimento às demandas da indústria. Trata-se de formação técnico-profissional, conforme definido em lei, que se caracteriza por atividades teóricas e práticas, metodicamente organizadas em tarefas de complexidade progressiva, destinada a jovens na faixa etária de 14 a 24 anos, mediante a celebração de contrato de aprendizagem com empresa ou instituição" (2007, p.29).

- Qualificação, aperfeiçoamento e especialização profissional: São ações de formação profissional, que visam ao desenvolvimento de competências profissionais requeridas pelo mercado de trabalho; à atualização, ampliação ou complementação de competências; e ao aprofundamento da formação profissional. A expectativa é de expressivo aumento da demanda com o crescimento da indústria" (2007, p.29).

- Educação profissional técnica de nível médio: "Educação Profissional: É condição essencial para o ingresso e o sucesso dos recursos humanos no mercado de trabalho e requisito das empresas para o aperfeiçoamento de bens e processos produtivos de qualidade, com impacto no aumento da sua produtividade. $O$ portifólio de atendimento à demanda industrial compreende: educação tecnológica, educação para o trabalho, assistência técnica e 


\section{trabalhonecessário}

issn: $1808-799 X$

ano 7 - número 8 - 2009

tecnológica. Estas ações são desenvolvidas em articulação com o ensino regular" (2007, p.29).

- Educação Superior: O SENAI vem ampliando expressivamente a sua presença na educação superior, por meio de cursos de graduação e pós-graduação, com predominância nos cursos de tecnologia voltados para a formação de tecnólogos" (2007, p. 30).

A proposta do SENAI, enquanto órgão que recebe verba pública e deveria atender à classe trabalhadora como um todo, é clara: excluir boa parte dos estudantes e incluí-los em outras redes de ensino, de preferência a pública ou privada, onde os cursos geralmente são mais baratos que desta instituição.

Para o SENAI a figura do "homem tocha" no quarteto fantástico lhe cai perfeitamente. Tal como o personagem, esse órgão se apresenta como vanguardista, moderno, ousado e desejado pelo público em geral. Propõe-se a ser o modelo de competência na área da educação que abrange a formação profissional. Suas atividades se estendem desde os cursos de tecnólogo até a pós-graduação stricto-sensu. Na verdade, em termos de inclusão social, o que ele faz é fulminar as chances de ascensão dos estudantes que não têm condições de acessar e permanecer em seus cursos. As esperanças cultivadas ao cursar o SESI viram cinza.

3. Mão de obra qualificada no Brasil: o resultado histórico da falta de investimento na Educação Básica

Para compreendermos as implicações acerca dos argumentos da CNI sobre a falta de mão de obra qualificada como causa do crescimento econômico letárgico, consideraremos que este fenômeno esconde a questão do desemprego enquanto conseqüência da necessidade do capital em criar exército industrial de reserva, podendo comprar o produto trabalho humano do modo como melhor lhe convier. Logo, flexibilizar a formação dos trabalhadores, intento da CNI e seu programa Educação para a nova indústria, nada mais é do que reorientar intelectualmente a população para vivenciar e aceitar sem resistências o regime de trabalho flexibilizado. 


\section{trabalhonecessário}

issn: $1808-799 \mathrm{X}$

ano 7 - número 8 - 2009

Historicamente a conformação do trabalhador à exploração do seu trabalho começa na sua formação escolar e profissional. A escola básica, atualmente, é concebida como o alicerce para o aluno obter condições intelectuais para cursar sua formação profissional de forma satisfatória para o mercado de trabalho e este seria o maior ponto de insatisfação do empresariado com a classe trabalhadora na atualidade: a mercadoria força de trabalho, enquanto insumo para o processo produtivo, apresenta baixa qualidade e prejudica os negócios na competição internacional.

Há algum tempo atrás, a formação profissional, no antigo regime de acumulação fordista, era de caráter restrito, grosso modo, como adestramento da mão-de-obra e de adaptação do trabalhador direto ao seu posto de trabalho. Para algumas empresas a formação profissional foi encarada como "estratégia operacional na busca da qualidade e da produtividade" (2006, p.137). Logo, a qualificação do trabalhador adquiriu caráter polivalente e a demanda por formação exigiu habilidades operacionais e comportamentais adequadas para executar tarefas repetitivas com paciência e disciplina. Segundo Cattani (2006. p.138), no regime fordista, a "qualificação humana e a competência profissional, até então valores socialmente reconhecidos-, são avaliadas quanto à capacidade de se executarem normas de produção". Para Saviani (2002) a "era das máquinas inteligentes" transferiu para as mesmas as operações intelectuais antes executadas pelo homem, tornando auto-regulável o processo de produção em si. Isso deveria deixar o ser humano mais "livre" em termos de tempo de trabalho, mas ao contrário, "o avanço tecnológico converte-se, sob as relações sociais de produção capitalista, em instrumento de maximização da exploração da força de trabalho, ampliando a marginalização social através do crescente desemprego mantido sob controle" (2002, p.21). O desemprego, antes, concebido enquanto fator da crise no estado de Bem-estar social, passa a ser o termômetro regulador das crises oriundas do desaquecimento da economia mediante aos ajustes do sistema financeiro internacional.

Resumindo, a crise do capitalismo vem do fato de que o desemprego estrutural é a forma do capital extrair mais - valia do trabalhador, de modo cada vez mais 


\section{trabalhonecessário}

issn: $1808-799 X$

ano 7 - número 8 - 2009

intensificado, de um número menor de pessoas, especificamente aquelas que trabalham e obtém renda financeira que as permite consumir. Podemos afirmar que o desemprego, no sistema capitalista, nunca será conjuntural. Ele é programado para ser estrutural e, portanto, cíclico conforme a demanda produtiva. É preciso entender que o desemprego estrutural é uma conseqüência da necessidade do capital em formar um quadro de mão de obra barata, ou melhor, um exército industrial de reserva. Portanto, se a educação capacitar intelectual e profissionalmente todas as pessoas para competirem no mercado em pé de igualdade, não estará cumprindo sua função na lógica do capital. Afinal, este precisa de dois tipos de contingente de mão de obra: um altamente qualificado e outro adequado às demandas "naturais" da produtividade. Contudo, independentemente da origem do trabalhador, o que o capitalista quer é reduzir o número de gente empregada, pagar menos e lucrar mais, extraindo ao máximo, do trabalho vivo, a mais-valia absoluta.

O atual problema no Brasil do século XXI foi que o exército industrial de reserva, devido ao não investimento na educação nas décadas de $80 / 90$, não conseguiu atender às demandas do sistema produtivo pelo desconhecimento e despreparo para lidar com o avanço tecnológico e científico. Há um contingente enorme de analfabetos funcionais formados na lógica fordista. Há leis que asseguram rigor na empregabilidade da mão de obra estrangeira em detrimento da nacional. Para o novo télos dos empresários, a ordem passou a ser investir o mínimo na formação de um exército de reserva mais qualificado.

Acreditamos que o que se esconde por trás da proposta da $\mathrm{CNI}$ em manter o SESI atendendo à formação de trabalhadores que necessitam mais do saber tácito (com cursos gratuitos) e o SENAI ofertando cursos (não gratuitos) de alta qualidade para desenvolver trabalhadores capazes de gerar conhecimento sistematizado, é uma agenda de formação de exército industrial com trabalhadores flexíveis. A CNI lançou mão da tese da qualificação desqualificando a educação em geral e, simultaneamente, sob a tese da requalificação, propondo soluções para a educação no Brasil. 


\section{trabalhonecessário}

issn: $1808-799 \mathrm{X}$

ano 7 - número 8 - 2009

Para o capital, a flexibilização, tanto do trabalho em si quanto da formação do trabalhador se constitui num meio de alterar não só as relações de trabalho, mas possibilita reestruturar constantemente as regulamentações concernentes ao mercado de trabalho, segundo Cattani e Holzmann (2006, p.131). Quanto à legislação, os autores afirmam que "segundo a ótica neoliberal, essas proteções serão tanto mais rígidas quanto for o leque de benefícios assegurados aos trabalhadores e quanto mais regulados forem as condições de venda e uso da força de trabalho". Quanto mais o empresariado industrial dominar a área da educação, a política educacional, mais poderá regulamentar e desregulamentar as relações trabalhistas com a desculpa de contratar ou demitir, pagar muito ou pouco conforme o nível de instrução do trabalhador.

Enfim, no Brasil dos anos 90, a política de Estado Mínimo se baseou exatamente no tipo de investimento estatal dedicado a desindustrializar, desnacionalizar e atender às demandas do capital financeiro e isso trouxe graves conseqüências tanto para a classe trabalhadora quanto para a burguesia como um todo. A população e suas necessidades ficaram em último plano em termos de investimento na área sócia. Apesar de o governo atual afirmar altos investimentos nesta área, faz de tudo para que eles não venham a pesar nos ombros dos empresários via impostos-daí a isenção fiscal em larga escala. Conclui-se que o investimento empresarial em educação não é uma benevolência social, nem somente um arranjo político. É antes de tudo uma necessidade econômica e financeira de acumular capital, de obter lucro.

3.Formação de Capital Humano e a educação ofertada para a classe trabalhadora

"O presidente da CNI, Armando Monteiro Neto, apresentou na quarta-feira, 12 de setembro, ao ministro da Educação, Fernando Haddad, o programa Educação para a Nova Indústria. O projeto da CNI prevê investimentos de R $\$ 10,45$ bilhões e a oferta de formação básica e profissional para 16,2 milhões de brasileiros até 2010 . $\mathrm{Na}$ ocasião, o ministro elogiou o escopo do projeto, as metas e a própria concepção do programa. No encontro, Haddad fez algumas sugestões para tornar os esforços do Serviço Social da Indústria (SESI) e do Serviço Nacional de Aprendizagem 


\title{
trabalhonecessário
}

issn: $1808-799 X$

ano 7 - número 8 - 2009

\begin{abstract}
Industrial (SENAI) mais articulado com as metas e programas governamentais. De acordo com o presidente da CNI, Fernando Haddad demonstrou ainda interesse em estreitar as relações do ministério com os programas desenvolvidos por SESI e SENAI.

O programa Educação para a Nova Indústria tem o objetivo de formar 2,3 milhões de alunos nos cursos de jovens e adultos, alcançar 848 mil matrículas em educação básica, 4 milhões de matrículas em educação continuada, 8,6 milhões de matrículas em formação inicial e continuada de trabalhadores, 482 mil matrículas em cursos de educação profissional técnica e de nível médio, entre outros." (Disponível em <http://implantacao.cni.org.br/lumis/main.jsp?lumPageld > Acesso em 06/02/2008).
\end{abstract}

A burguesia industrial brasileira aprofundou sua inserção no debate educacional na década de 80 (RODRIGUES, 1998) quando a procura por novos mercados demandou um novo télos industrial, cuja finalidade foi elaborar estratégias para recriar certa 'institucionalidade' onde o Estado fosse o agente produtivo e normativo, um modelador da educação e da formação profissional de forma que esta pudesse atender aos novos padrões. Logo, as demandas do setor industrial foram explicitadas em vários documentos anteriores à divulgação do programa Educação para a nova indústria. .Segundo Rodrigues, a documentação mais relevante acerca do assunto é: "Competitividade Industrial- uma estratégia para o Brasil" (1988); "Educação Básica e formação profissional" (1993), "SENAI, Desafios e Oportunidades" (1994), e "Modernização das Relações Trabalhistas" (1995)" (1998, p.98).

O padrão de acumulação flexível demandou uma procura por novos nichos na busca pela competitividade no mercado internacional. Instaurou-se a "febre" de modernização via progresso tecnológico. Para abrir passagem para o progresso a CNI precisou remover tr es tipos de barreira, segundo Rodrigues. Foram elas: o Estado, a formação de Recursos Humanos e a Cultura Empresarial.

No que diz respeito ao Estado, o foco foi na exigência, por parte do empresariado, foi exigir subsídios e isenções fiscais para suprir os gastos feitos em investimento nas áreas de ciência e tecnologia. Assim, o fundo público proveniente dos impostos ficou reduzido para a área social.

A formação de Recursos Humanos se constituiu enquanto barreira na medida o "analfabetismo, abaixa cobertura da população escolarizável (tanto no nível secundário quanto superior), e a reduzida integração universidade-empresa" eram 


\section{trabalhonecessário}

issn: $1808-799 X$

ano 7 - número 8 - 2009

vistos como problemas que não podiam ser ignorados, pois afetavam a produção em si. Na medida em que os trabalhadores despreparados para lidar com o avanço tecnológico atravancavam a competitividade, compreendeu-se que o ensino teria que se adequado às necessidades econômicas urgentemente. Fosse à educação básica, fosse à formação tecnológica. Rodrigues atentou para o fato de que no documento Competitividade Industrial a CNI dirigiu quase toda a sua preocupação para a Universidade, com objetivo de subordinar a pesquisa e o ensino. Nesse ponto, o autor afirma que a $\mathrm{CNI}$ solicitou ao governo que este fosse mais rígido com a transferência de recursos para as universidades. Isso deveria ser feito após uma avaliação dos centros de ensino e dos programas de pós-graduação, onde os incentivos fiscais ajudariam a promover a canalização de recursos privados para o sistema público de ensino, desde que essas empresas participassem das decisões sobre o destino desses recursos. Logo, se conclui que a adequação da formação de mão de obra atingiu, enquanto necessidade do capital, a todos os níveis e modalidades de ensino.

A tão desejada competitividade só poderia se efetivar quando as ações entre empresas e universidades ou centros de pesquisa estivessem em acordo e andamento. Portanto, fica claro que a "culpabilização da educação básica" pelo crescimento econômico letárgico, pertinente ou não, esconde uma proposta de investimento em longo prazo que visa, realmente, afetar os três graus de ensino e diretamente, o nível superior remodelando-os para beneficiar o capital. Daí veio a necessidade de remover a terceira barreira: a Cultura Empresarial. Com a implantação de uma política tecnológica, o insumo principal era o capital humano, o centro dos investimentos agora deveria ser a formação profissional qualificada. Atualmente, essa mudança de mentalidade fica clara não só nos programas de educação em gestão empresarial do IEL, mas pelo próprio programa Educação para a nova indústria. Sobre a mesma década, RUMMERT (2000) afirma que a CNI passou a formular propostas para o governo federal, interferindo diretamente na "Assembléia Nacional Constituinte, na política econômica e no plano das políticas públicas, em particular aquelas vinculadas à educação e à formação profissional" 


\section{trabalhonecessário}

issn: $1808-799 X$

ano 7 - número 8 - 2009

(2000. p. 76). Atualmente o processo parece estar se repetindo com a parceria CNI e Senado.

O projeto hegemônico da burguesia, segundo Rodrigues (1998), já se desenhava anteriormente, em vários documentos da $\mathrm{CNI}$, os quais deixavam claras as propostas pedagógicas que deveriam ser "empreendidas, fundamentalmente pelo SESI e SENAl" (1997, p.1). Podemos afirmar, então, que o projeto Educação para a Nova Indústria, enquanto uma re-edição das antigas propostas, carrega, sem dúvida, a certeza de que o SESI e o SENAI poderão funcionar enquanto centros formadores de capital humano, para que se crie um "estoque" de mão de obra mais qualificado. Segundo os estudos de Rummert (2002) as propostas educacionais da CNI tiveram como fundamento a Teoria do Capital Humano (TCH), a qual é "o principal enquadramento teórico usado para definir o sentido da relação trabalho - educação no capitalismo contemporâneo" (GENTILLI, 2002, p.47). A TCH traz em seu bojo original a idéia de que é possível, para todos os países, a conquista do estado de pleno emprego, como isso, por si só, anulasse as classes sociais e a exploração. A $\mathrm{TCH}$ vincula a educação como fator de desenvolvimento econômico e meio que possibilita a distribuição de renda por conta desse crescimento econômico potencializado.

Após a crise econômica mundial da década de 70 , a TCH não conseguiu sustentar o que Gentili (2002) definiu como "a promessa integradora da escola". A promessa se compunha de um conjunto de estratégias orientadas para um mercado de trabalho em expansão, onde a escola constituiria um espaço contribuidor para a integração econômica da sociedade com a finalidade de formar um contingente de força de trabalho a ser incorporada gradualmente no mercado. Quanto ao Estado, a promessa integradora consistia no fato deste se concentrar no planejamento e, principalmente, na captação de recursos financeiros, atribuição e distribuição de verbas para o sistema educacional. Segundo Gentili "Dessa forma, o Estado contribuiria tanto para o aumento da renda individual-derivada do capital humano individual-, quanto para o aumento da riqueza social (derivada de um incremento no estoque de capital humano social)". 


\section{trabalhonecessário}

issn: $1808-799 \mathrm{X}$

ano 7 - número 8 - 2009

O autor afirmou que a mudança de lógica com o advento do sistema de acumulação flexível se deu na troca da promessa do pleno emprego pela da empregabilidade. A centralidade dada à coletiva-competitividade das empresas, a economia nacional etc. - deixa de vigorar e o caráter privado e individualista constrói - arcabouço da empregabilidade. Nesta lógica o indivíduo passa a ser responsabilizado pelas suas próprias opções de investimento em educação, caso não ganhe posições competitivas no mercado. Isso é o que o autor define como "desintegração da promessa integradora da escola". A Lógica que perpetuou no modelo de acumulação flexível foi a de que "a escola é uma instância de integração dos indivíduos ao mercado, mas não todos podem ou poderão gozar dos benefícios dessa integração já que, no mercado competitivo, não há espaço para todos" (2002, p.52). Qualquer que seja a instituição, tal qual o SESI e o SENAI, na ótica empresarial, em termos de oferta para a classe trabalhadora, terá caráter dual em sua estrutura de ensino para permitir a exclusão de trabalhadores desqualificados e propiciar um leque de escolhas entre os qualificados.

No atual contexto da aprovação do programa da CNI enquanto proposta para a educação, não nos admira que as idéias da Comissão de Educação do Senado um dos centros da nossa atenção neste artigo - se voltem para solucionar os "problemas da Educação Básica e da Formação Profissional na ótica dos "educacionistas". O objetivo parece ser contemplar o capital industrial formando mão de obra e o financeiro ampliando os empréstimos para novos investimentos na educação.

Enfim, ao mesmo tempo em que surgem projetos revolucionários por parte do governo, coincidentemente as propostas da CNI tramitam no Senado. Ao colocar o SESI e o SENAI como mediadores da formação de capital humano, ou melhor, centros produtores de mercadoria - educação, a indústria parece estar procurando garantir um espaço lucrativo e competitivo diante dos empresários do setor de bens e serviços. Essa busca por mão de obra qualificada é uma questão de sobrevivência do capital industrial, pois não Ihe interessa a mão de obra formada pelas mãos dos empresários da educação, já que a qualidade é de procedência duvidosa e não atende às suas demandas. Por tal motivo, segundo Rodrigues (2007), mesmo que o 


\section{trabalhonecessário}

issn: $1808-799 \mathrm{X}$

ano 7 - número 8 - 2009

interesse comum da burguesia de serviços educacionais e da burguesia industrial seja transformar a Educação em mercadoria, há uma disputa conflituosa no Poder Executivo do nosso Estado. O que nos chama atenção é que o poder em disputa na atualidade é o Senado. Não podemos saber ao certo se é um poder em disputa ou em concessão, dada a postura voluntariosa do presidente da Comissão de educação: senador Cristovan Buarque. Por tal motivo, dentro deste artigo, trataremos da posição do Senado ao defender o "Educacionismo" e ao mesmo tempo corroborar com as propostas da CNI.

4. Educacionistas unidos poderiam propor uma Revolução para beneficiar a classe trabalhadora?

Escolhemos a figura do "homem elástico", capaz de se esticar abraçando tudo que pode e deseja, se esgueirar nas horas difíceis para fugir dos confrontos para representar o Senado brasileiro. Segundo Cristovan Buarque, presidente da Comissão de Educação do Senado, a nova ideologia -de cunho completamente contraditório- capaz de abraçar e amarrar ao mesmo tempo os ideais da classe trabalhadora, das frações da classe burguesa, das demandas dos organismos multilaterais e do próprio governo, protegendo o Brasil da crise da educação é o Educacionismo. A saber, que os educacionistas são na verdade os empresários, segundo suas entrevistas ao Jornal O Globo (16/02/2008), o mesmo que divulgou as matérias sobre o "Apagão da mão de obra". Tal feito só seria possível, segundo o Senador, através do lema que estremece qualquer marxista: ' $E m$ vez de "proletários de todo o mundo uni-vos", o grito deve ser: "Educacionistas de todo o Brasil, univos!"'(2007, p.33, disponivel em www.cni.org.br).

Neste último tópico, a intenção é discutir em que medida a parceria públicoprivada poderia realmente melhorar a qualidade na educação. Sendo assim, consideramos que a proposta da CNI, na versão 2007, apresentada à Comissão de Educação pela senadora Marisa Serrano (PSDB-MS/ Ensino Médio e Profissionalizante), pode se configurar como uma re-edição de propostas anteriores feitas desde a década de 90 (RUMMERT, 1999) com as devidas alterações para 


\section{trabalhonecessário}

issn: $1808-799 X$

ano 7 - número 8 - 2009

atender ao télos industrial da atualidade: o desenvolvimento sustentável do país (disponível em <http//: implantacao.cni.org.br/lumis/main.jsp?lumPagel> último acesso em 5/2/2008). Ressaltamos que a proposta tem sido difundida e amplamente apoiada pelo senador Cristovam Buarque (PDT-DF), atual presidente da Comissão de Educação do Senado, o qual considera que o ambicioso projeto, traz a educação, a ciência e a tecnologia como insumos para o avanço do Brasil (leia-se crescimento econômico).

Buarque, em entrevista concedida à Revista da Indústria (jan. 2008, p.32-33) afirmou que a Nação precisava abraçar uma causa comum: "o Educacionismo". Esta palavra de ordem traduziria a "nova ideologia" capaz de dar à população o que, segundo ele, "as distantes soluções revolucionárias" não foram capazes de oferecer concretamente: uma "Escola Igual". Para tanto o governo estaria criando um novo programa, mas não houve explicitação de qual e como será. É interessante observar que neste mesmo período as propostas da CNI foram apresentadas ao Ministério da Educação (12/09/2007), à Comissão de Educação e Cultura da Câmara dos Deputados (17/10/2007) e à Comissão de Educação do Senado (22/11/2007). É preciso ressaltar também que foi assinado um protocolo de intenções com a CAPES/MEC (06/12/2007) consolidando a produção do conhecimento enquanto mercadoria. Citemos a criação de cursos de graduação e pós-graduação na área de tecnologia dentro do SENAI. A parceria com a CAPES consolida não apenas sua participação na educação superior, mas abre portas para a parceria entre a universidade pública e a indústria. Esta parceria pode vir a se tornar mais que público-privada. Pode vir a ser o público não-estatal, ou seja, acordos entre o setor público e o privado que diluem as fronteiras a ponto de permitir a privatização de setores públicos dentro de instituições que são públicas também. Por isso afirmamos boa parte das propostas que interessam ao governo, à Comissão de Educação, Cultura e Esportes do Senado provavelmente são aquelas oriundas do empresariado da indústria.

Segundo Buarque, para obtermos um modelo de desenvolvimento sustentável que "assegure a mesma chance entre as gerações" dentro de "um sistema social e econômico eficiente, que garanta ao mesmo tempo dinamismo econômico e cultural, 
issn: $1808-799 \mathrm{X}$

ano 7 - número 8 - 2009

estabilidade social e política, como base para a revolução na educação, e o equilíbrio ecológico" os educacionistas precisarão se unir com a sociedade em geral (Revista da Indústria, 2008). Dada essa afirmação, se faz imprescindível identificar como a parceria público-privado é entendida pela $\mathrm{CNI}$, para assim concluirmos como a educação acaba se construindo como campo de investimento para a nova cultura empresarial:

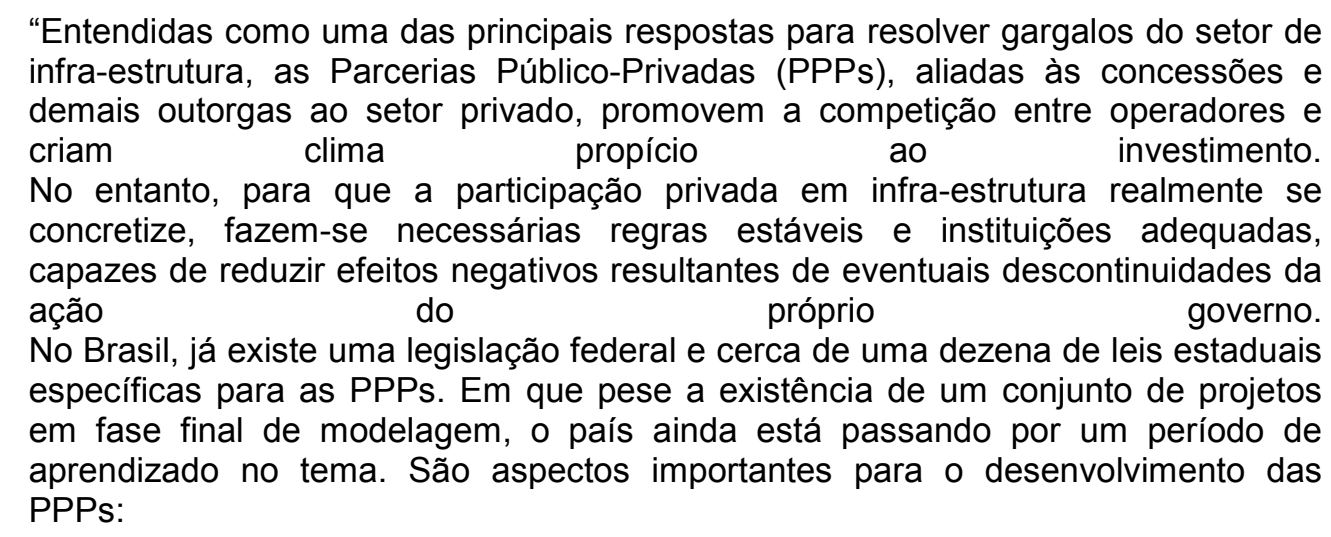

O entendimento do papel do fundo garantidor pelos investidores privados, sobretudo os estrangeiros;

A percepção de que as PPPs constituem um mecanismo para provisão de serviços e não oportunidades de obras; e

As garantias de estabilidade regulatória;

Deve-se ressaltar, ainda, que as PPPs não podem ser encaradas como a única solução para todos os problemas de infra-estrutura nacional. As privatizações, as concessões e a desregulamentação de setores devem ser consideradas igualmente imprescindíveis na agenda da infra-estrutura brasileira." (Disponível em www.cni.org.br acesso em 20/02/2008, grifos nossos)

Afirmamos que o governo prima por garantir que a indústria não tenha prejuízos garantia onera diretamente os cofres públicos apesar do aparente investimento do setor privado; representa uma perda de direitos para a classe trabalhadora, desmonta a Universidade Pública por dentro subordinando a produção do conhecimento ao mercado e às rédeas do setor privado e mantém a dualidade estrutural do ensino apesar de se propor a ofertar educação de qualidade para toda a população. Como exemplo desse acorrentamento, podemos observar o texto do relatório do Ciclo de Audiências Públicas: Idéias e Propostas para a Educação 
issn: $1808-799 \mathrm{X}$

ano 7 - número 8 - 2009

Brasileira e o Plano de Desenvolvimento da Educação, relativamente ao ensino superior, pesquisa e formação, cujo responsável foi o senador Marcos Maciel.

"O Plano de Desenvolvimento da Educação (PDE) do Governo Federal tem entre suas premissas a visão sistêmica da educação. Ao que se depreende dos documentos produzidos pelo Ministério da Educação (MEC) em relação ao plano, a articulação das políticas de educação realizadas no conjunto do Governo é condição imprescindível para que o País possa dar um salto na qualidade da educação básica, sem, com isso, negligenciar, os avanços de que precisa na área de Ciência e Tecnologia.

A par disso, em paralelo às ações de melhoria da educação básica, o $P D E$ congrega instrumentos normativos e ações, de diversas naturezas, que direcionam a atuação do Poder Executivo Federal. No que tange à preocupação com a área de pesquisa propriamente dita, vale mencionar as ações ou estratégias a seguir descritas.

1 - Aproximação entre setor produtivo e universidades envolvidas com pesquisa aplicada

Com amparo na Lei $n^{\circ} 11.487$, de 15 de junho de 2007, que envolve incentivo à Ciência e Tecnologia, a medida beneficiará, 2 com renúncia fiscal, empresas que investirem em projetos de inovação científica e tecnológica desenvolvidos por institutos públicos.

A candidatura das empresas aos incentivos fiscais deve ser formalizada em projeto de investimento em pesquisa a ser desenvolvida por instituição especializada, o qual deve ser previamente submetido à aprovação de comissão de especialistas dos ministérios da Educação, do Desenvolvimento, Indústria e Comércio Exterior e da Ciência e Tecnologia.

A previsão é de que, em 2008, sejam concedidos benefícios fiscais de até $R \$ 150$ milhões, alocados no orçamento fiscal da União para os próximos exercícios;"

(Disponível em < http://www.senado.gov.br/web/comissoes/ce/documentos/PDERelatorioSetorial-SenMarcoMaciel-EnsinoSuperior-PesquisaeFormacao.pdf> acesso em 21/02/2008)

Quanto à Educação Profissional, curiosamente, o Senador Paulo Paim trata

de criticar do dinheiro público das escolas técnicas para o sistema $\mathrm{S}$, em detrimento às escolas federais:

"A capacitação de técnicos e outros profissionais para as indústrias, a exemplo do que ocorre nas entidades do Sistema "S" ligados ao setor, de uma forma geral, tem um custo significativo. O custo de oportunidade da oferta de educação profissional no ensino regular, por sua vez, é ainda mais expressivo e as pessoas saem da escola sem a preparação mínima para o trabalho. Há prejuízos para as pessoas, que ficam impedidas de exercer atividades de maior complexidade técnica, mas também para as empresas, que perdem competitividade. Desse modo, a política de "apagar incêndio" para suprir a deficiência do sistema educacional e elevar, minimamente o desempenho dessas pessoas no trabalho envolve um gasto adicional muito grande.

Advertiu-se, entretanto, no que tange à ampliação da educação profissional por meio da expansão da rede federal de escolas técnicas, a iminente ameaça do Projeto de Lei Complementar (PLP) $\mathrm{n}^{\circ} 1$, de 2007, que altera a Lei de Responsabilidade Fiscal para limitar o crescimento das despesas com pessoal no serviço público federal. De acordo com a proposição, o aumento real da folha de pagamento da União ficará sujeito a um teto de $1,5 \%$ ao ano. De certo modo, a medida se dá na contramão do fortalecimento do Estado indutor do 


\section{trabalhonecessário}

issn: $1808-799 \mathrm{X}$

ano 7 - número 8 - 2009

desenvolvimento. É o caso de examinar mais detidamente essa proposta, com vistas a não emperrar o processo de desenvolvimento educacional do País."

Contraditoriamente, no mesmo documento parece considerar muito positivo o trabalho do Sistema S em atender às demandas que o governo não dará conta por precisar poupar despesas, pois a aprendizagem industrial de caráter gratuito via SENAI parece ser o suficiente para a classe trabalhadora. Ele destaca sem nenhum pudor que entre os cursos técnicos, apenas o SENAI de São Paulo não possui cursos pagos, graças à benevolência do empresariado.

Enfim, se torna imprescindível observarmos como os interesses particulares do governo, ao se desresponsabilizar para com a educação pública e gratuita, e do empresariado em adaptar à educação como um todo às demandas do capital, se convergem estrategicamente e de forma dialógica num ponto só: oferecer outro tipo de educação que poderíamos classificar como "excludentemente includente" para a classe trabalhadora.

A gratuidade dos cursos do SESI pode ser contestada na medida em que este recebe verba federal, configurando não uma concessão para a população, mas uma obrigação desde o momento em que o dinheiro se desvia das escolas técnicas federais, das universidades, da educação básica como um todo. Contudo, o SENAI deve ser observado como o ponto mais crítico na medida em que as verbas repassadas pelo governo podem não garantem cursos gratuitos, principalmente numa instituição que abrange a formação profissional em nível médio e superior, incluindo a pós -graduação stricto-senso. Numa nota divulgada no site da CNI, Buarque teria afirmado que "o Programa preenche uma grande lacuna do setor público", se referindo ao fato de que a CNI oferecerá "30\% de atendimento à educação profissional via SESI e SENAl" (2007, p.6).

Repensando a preocupação da CNI com o apagão da mão de obra no país, retomamos as matérias exibidas pelo jornal O Globo, citadas anteriormente, a do dia 3 de novembro de 2008, cujo título foi "Sistema $S$ tem recursos de sobra, que escapam do controle do governo", trouxe a afirmação de que a CNI calculava os orçamentos do SESI e SENAI em R\$ 2,2 bilhões até setembro do ano passado. $O$ sistema Integrado de Administração Financeira (Siafi) afirmou que o valor repassado 


\section{trabalhonecessário}

issn: $1808-799 \mathrm{X}$

ano 7 - número 8 - 2009

pela União às cinco maiores entidades do Sistema $S$ em 2006, representava mais que o dobro recebido pelo Ministério da Educação para que este aplicasse nas escolas técnicas.

Confirmamos assim que existem estratégias coletivas na parceria públicoprivado, onde o SESI e o SENAI são os interlocutores com as escolas técnicas e universidades. Entendemos que os cursos oferecidos pelo SESI e SENAI, os quais recebem o dobro da verba das escolas técnicas de caráter público representa não só uma perda de direitos para a classe trabalhadora, mas uma afronta à população que tem que pagar por algo que já está pago. Tal afronta se constitui como um ato indecoroso quando o próprio governo, prioritariamente o Senado, divulga publicamente que os empresários em geral estariam 'ajudando' a melhorar e ampliar a oferta da educação básica e da formação profissional investindo uma boa parcela de dinheiro privado ao mesmo tempo em que recebe, ainda, poucas isenções fiscais. Enquanto isso a população paga impostos altíssimos para manter a previdência funcionando.

Acreditamos que a parceria entre o SESI e a CAPES/MEC irá fomentar a ampliação dos cursos pagos de pós-graduação e graduação de forma a propiciar uma competição sutil entre o as burguesias de serviços e a industrial, nas áreas de ciência e tecnologia. Principalmente no que diz respeito à educação à distância na área de Tecnologia da Informação e Ciência ${ }^{1}$ Assim é possível crer que todo esse movimento poderá atingir diretamente a Universidade Pública, já ameaçada pelo REUNI. Pode-se afirmar, então, que a parceria entre os educacionistas é uma estratégia que vai além da instauração da subordinação da produção do conhecimento consentida por dentro, pelo próprio governo. Infelizmente ela atinge diretamente o direito da classe trabalhadora em se educar pelo trabalho e não para viver para o trabalho, especificamente, o explorado.

CONCLUSÕES:

\footnotetext{
${ }^{1}$ Educação à distância na reformulação da educação superior brasileira. LIMA, Kátia. 2006
} 


\section{trabalhonecessário}

issn: $1808-799 X$

ano 7 - número 8 - 2009

Este artigo abordou o tema da falta de mão de obra qualificada no Brasil para mostrar os movimentos do capital industrial, junto ao Estado, orientados para propiciar tempos e espaços de inculcação ideológica na sociedade. Através dos meios de comunicação em massa, no caso o Jornal O Globo, a CNI e o Senado Cristovam Buarque se utilizam da tese da desqualificação ao se referirem à educação básica e formação profissional de origem pública, e propõem, sob o signo da tese da requalificação, agências formadoras que supostamente poderão ajudar a "salvar" a educação brasileira do caos. Essas são as duas linhas de ação que compõem o novo télos do capital industrial brasileiro: formação flexível de capital humano.

Conforme os destaques acima e o próprio documento do programa Educação para a Nova Indústria há uma proposta teórica bem definida para a educação destinada à classe trabalhadora e estratégias práticas de viabilização desta. Esta proposta é a formação de capital humano, a qual deve se dar de forma abrangente, iniciando na educação básica e se estendendo até a universidade de forma interligada. Isso implica interferir não só na formação profissional do indivíduo, mas "mas também investir na formação de hábitos e atitudes positivas em relação ao trabalho, à vida comunitária e ao regime democrático" (2007, p.37).

Portanto, não basta para o capital industrial ampliar suas redes com agências formação para gerar capital humano. É preciso flexibilizar a educação como um todo para alcançar certo padrão de qualidade no ensino, de forma que o trabalhador se torne uma fonte segura extração de mais valia relativa e absoluta através do trabalho vivo. Há dois movimentos paralelos que o capital, através da $\mathrm{CNI}$ vem fazendo. O primeiro constitui em interferir, junto ao governo federal, na legislação: tanto na trabalhista flexibilizando-a cada vez mais, quanto nas leis que regem a educação, de modo a flexibilizar o ensino.

O segundo movimento consiste numa estratégia dialética: a CNI, via meios de comunicação em massa, recupera a tese da qualificação sinalizando à sociedade em geral a falta de mão de obra adequada ás demandas do crescimento econômico auto-sustentável. Faz isso desqualificando o ensino público, da educação básica à educação superior. Concomitantemente, como afirmamos ao longo do texto, propõe 


\section{trabalhonecessário}

issn: $1808-799 \mathrm{X}$

ano 7 - número 8 - 2009

a requalificação desta mesma mão de obra via instituições preparadas por ela mesma: SESI e SENAI. Com uma práxis teórica e política bem definida, em parceria com o governo a CNI procura manter a classe trabalhadora dócil e flexível para ser amplamente explorada.

Fora dessas agências de formação, consagradas enquanto "modelo educacional", a população em geral, só tem como alternativa o ensino público que vem maciçamente sendo desqualificado e sucateado; ou então a rede privada com sua educação-mercadoria (RODRIGUES, 2007) de procedência duvidosa, principalmente para o setor industrial que precisa de trabalhadores bem qualificados. Configura-se assim mais uma forma de dualidade estrutural no ensino.

Enfim, refletir até que ponto o governo Lula se empenha em democratizar uma educação pública e gratuita, voltada para a formação profissional da classe trabalhadora, hoje, é uma tarefa ético - política que precisa ser enfrentada pelos intelectuais orgânicos da classe trabalhadora. Infelizmente os movimentos políticos entre a burguesia e o Estado são muitas vezes sutis articulados e extremamente rápidos, o que consiste num desafio cuja prerrogativa é perceber que por trás dos benefícios concedidos aos trabalhadores, se esconde o interesse do capital em gerar lucro. Por tal motivo este artigo partiu de uma simples coletânea de matérias publicadas em um jornal para, a partir do discurso do apagão da mão de obra qualificada, revelar algumas estratégias bem definidas entre a burguesia industrial e o Estado que se destinarão, nos próximos anos, a manter a educação destinada à classe trabalhadora sob seu controle.

\section{BIBLIOGRAFIA:}

BOITO Jr. Política Neoliberal e sindicalismo no Brasil. São Paulo: Xamã, 1999.

BUARQUE, Cristovam. Nossa causa comum: o educacionismo. Revista da Indústria Brasileira, Brasília: 2007, p.32-33.Disponível em www.cni.ogr

CATTANI, Antônio David. HOLZMANN, Lorena.(orgs.) Dicionário de Trabalho e Tecnologia. Porto Alegre: Ed. Da UFRGS, 2006.

CUNHA. Luiz Antônio. O Zigue-Zague no Ministério da Educação: uma visão da educação superior. Revista Contemporânea da Educação, $\mathrm{n}^{\circ}$ 1, abril, 2006. 


\section{trabalhonecessário}

issn: $1808-799 X$

ano 7 - número 8 - 2009

Disponível

em

http://www.educacao.ufrj.br/revista/indice/numero1/artigos/conjuntura.php

CONFEDERAÇÃO NACIONAL DA INDÚSTRIA. Educação Para a Nova Indústria: uma ação para o desenvolvimento sustentável do Brasil / Confederação Nacional da Indústria, Serviço Social da Indústria, Serviço Nacional de Aprendizagem Industrial. - Brasília: CNI, 2007. Disponível em <http://implantacao.cni.org.br/lumi. jsp?lumPageld> . Acesso em 04 fev.2008.

GALVÃO, Andréa. O neoliberalismo na perspectiva marxista. 2007. (inédito. Mímeo)

HARVEY, David. A Condição Pós- Moderna. São Paulo: Edições Loyola, 1992.

LIMA, Kátia. Reforma Universitária: dimensões e perspectivas. Financiamento da educação Superior Brasileira nos anos de neoliberalismo. Alínea . 2006, p. 27-41.

LOMBARDI, José Claudinei. SANFELICE. José Luiz. SAVIANI, Dermeval. (orgs.) Capitalismo, Trabalho e Educação. Campinas, SP: Autores Associados, HISTEDBR, 2002.

MARX, Karl. O Capital: São Paulo: Ciências Humanas LTDA, livro 1, Capítulo VI, $1^{\text {a }}$ ed., 1978.

O APAGÃO DA MÃO DE OBRA. Jornal O Globo. Rio de Janeiro, 29 de out. à 04 nov.de 2007, Caderno de Economia.

RICARDO, Antunes. A Desertificação Neoliberal no Brasil: Collor, FHC e Lula. Campinas, SP: Autores associados, $2^{a}$ ed., 2005.

RODRIGUES, José. O Moderno Príncipe Industrial: o pensamento pedagógico da Confederação Nacional da Indústria. Campinas, SP: Autores Associados, 1998.

associados, 2007.

Os empresários e a educação superior. Campinas: Autores

RUMMERT. Sonia Maria. Educação e Identidade dos Trabalhadores: as concepções do capital e do trabalho. São Paulo: Xamã; Niterói: Intertexto, 2000.

http://www.senado.gov.br/sf/atividade/Comissoes/CE/CicloAudPubPDE.asp

http://www.senado.gov.br/web/comissoes/ce/documentos/PDE-RelatorioSetorialSenPauloPaim-EnsinoTecnicoeProfissionalizante.pdf

http://www.senado.gov.br/web/comissoes/ce/documentos/PDE-RelatorioSetorialSenMarcoMaciel-EnsinoSuperior-PesquisaeFormacao.pdf 
issn: 1808-799X

ano 7 - número 8 - 2009

http://www.senado.gov.br/web/comissoes/ce/documentos/PDE-RelatorioSetorialSenAntonioCarlosValadares-EnsinoSuperior-EnsinoeExtensao.pdf

http://www.senado.gov.br/web/comissoes/ce/documentos/PDE-RelatorioSetorialSenMarisaSerrano-EnsinoMedio.pdf 